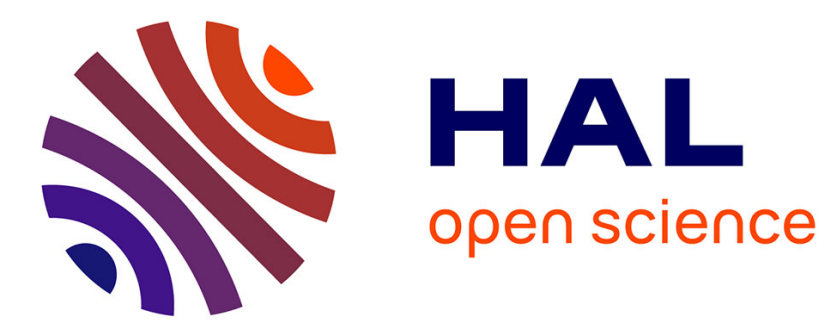

\title{
Binary and ternary cluster integrals of polymer segments as determined by small angle neutron scattering
}

\author{
K. Okano, E. Wada, K. Kurita, H. Hiramatsu, H. Fukuro
}

\section{To cite this version:}

K. Okano, E. Wada, K. Kurita, H. Hiramatsu, H. Fukuro. Binary and ternary cluster integrals of polymer segments as determined by small angle neutron scattering. Journal de Physique Lettres, 1979, 40 (7), pp.171-172. 10.1051/jphyslet:01979004007017100 . jpa-00231599

\section{HAL Id: jpa-00231599 https://hal.science/jpa-00231599}

Submitted on 1 Jan 1979

HAL is a multi-disciplinary open access archive for the deposit and dissemination of scientific research documents, whether they are published or not. The documents may come from teaching and research institutions in France or abroad, or from public or private research centers.
L'archive ouverte pluridisciplinaire HAL, est destinée au dépôt et à la diffusion de documents scientifiques de niveau recherche, publiés ou non, émanant des établissements d'enseignement et de recherche français ou étrangers, des laboratoires publics ou privés. 
Classification

Physics Abstracts

$36.20-61.12$

\title{
Binary and ternary cluster integrals of polymer segments as determined by small angle neutron scattering
}

\author{
K. Okano \\ Department of Applied Physics, Faculty of Engineering, \\ University of Tokyo, Bunkyo-ku, Tokyo, Japan \\ E. Wada, K. Kurita, H. Hiramatsu and H. Fukuro \\ College of Science and Technology, Nihon University, \\ Kandasurugadai, Chiyoda-ku, Tokyo, Japan
}

(Reçu le 8 janvier 1979, accepté le 15 février 1979)

\begin{abstract}
Résumé. - On analyse à l'aide de la théorie de Moore les résultats expérimentaux de diffusion de neutrons aux petits angles par des solutions semi-diluées de polystyrène dans le cyclohexane deutéré au voisinage de la température $\theta$ obtenus par Cotton et al. et on détermine les valeurs des intégrales de vertex à deux et trois corps.
\end{abstract}

Abstract. - The results of small angle neutron scattering by semi-dilute polystyrene solutions in deuterated cyclohexane near the $\theta$ temperature (Cotton et al. [3]) are analysed using the theory of Moore [2] and the values of binary and ternary cluster integrals are determined.

In a previous paper [1] we have reported the measurement of small angle X-ray scattering (SAXS) by semidilute solutions of polystyrene in poor solvents such as methyl ethyl ketone and cyclohexane, and showed that the results were successfully analysed by the recent theory of Moore [2]. Using this theory we were able to obtain the values of ternary cluster integrals in addition to the binary cluster integrals of polymer segments in these semi-dilute, poor solvent, solutions.

In the present note we show that the results of the small angle neutron scattering (SANS) by semidilute solutions of polystyrene in deuterated cyclohexane, reported by Cotton et al. [3] also conform to the above mentioned theory and the temperature dependency of binary and ternary cluster integrals of polystyrene in the neighbourhood of the $\theta$ temperature $\left(38^{\circ} \mathrm{C}\right.$ in this case) can be determined.

We are concerned with the semi-dilute, poor solvent, solutions defined by the following inequalities :

$$
\begin{aligned}
& \frac{4 \pi}{3}\left(\frac{1}{6} N b^{2}\right)^{3 / 2} \gtrsim \frac{N}{\rho} \\
& Z_{1} \equiv \frac{\beta_{1}}{b^{3}} N^{1 / 2}<1 \\
& Z_{2} \equiv \frac{\beta_{2}}{b^{6}}<1 .
\end{aligned}
$$

Here $b^{2}$ is the mean square length of a polymer segment, $N$ the number of segments in a polymer chain, $\rho$ the overall number density of segments in solution, and $\beta_{1}$ and $\beta_{2}$ are respectively the binary and ternary cluster integrals of polymer segments in solution. Then the density-density correlation function of polymer segments in semi-dilute poor solvent solutions as calculated by Moore leads to the angular dependence of the intensity of SANS (or SAXS) in the intermediate momentum range

$$
\begin{aligned}
& \left(\left(\frac{1}{6} N b^{2}\right)^{-1 / 2}<q<b^{-1}\right): \\
& I(q)=I(0) \frac{1}{1+\xi^{2} q^{2}} \\
& \frac{1}{\xi^{2}}=12 \frac{\beta_{1}}{b^{2}} \rho+36 \frac{\beta_{2}}{b^{2}} \rho^{2} .
\end{aligned}
$$

The momentum transfer, $q$, is given by

$$
q=\frac{4 \pi}{\lambda} \sin \frac{\theta}{2}
$$

where $\lambda$ is the incident wave length and $\theta$ is the scattering angle. As in the previous paper [1], we use, instead of the quantities $N, b^{2}, \beta_{1}, \beta_{2}$ and $\rho$, the observable quantities $M, A^{2}, B_{1}, B_{2}$ and $C$ defined respectively by the following relations,

$$
\begin{aligned}
M A^{2} & =N b^{2}, \\
M^{2} B_{1} & =N^{2} \beta_{1}, \\
M^{3} B_{2} & =N^{3} \beta_{2}, \\
C & =\rho \frac{M}{N_{\mathrm{A}}},
\end{aligned}
$$




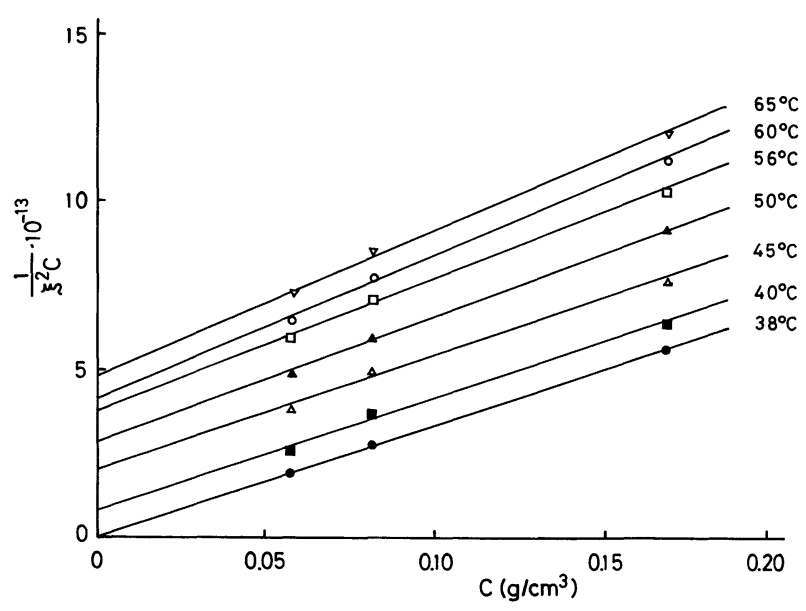

Fig. 1. - Plots of $1 /\left(\xi^{2} C\right) v s$. $C$ for a solution of hydrogenous polystyrene in deuterated cyclohexane at various temperatures.

where $M$ is the molecular weight of a polymer molecule and $N_{\mathrm{A}}$ is the Avogadro number. Then eq. (3) reduces to

$$
\frac{1}{\xi^{2} C}=12 N_{\mathrm{A}} \frac{B_{1}}{A^{2}}+36 N_{\mathrm{A}}^{2} \frac{B_{2}}{A^{2}} C .
$$

We proceed to analyse the SANS data by Cotton et al. [3] for semi-dilute solutions of polystyrene (molecular weight 1400000 ) in deuterated cyclohexane near the $\theta$ temperature $\left(38^{\circ} \mathrm{C}\right)$. We have used the values of the screening length $\xi$ as given by table IV in the paper cited and plotted $1 /\left(\xi^{2} C\right)$ against $C$. As shown in figure $1,1 /\left(\xi^{2} C\right)$ depends almost linearly on $C$ in accordance with the theoretical prediction (5).

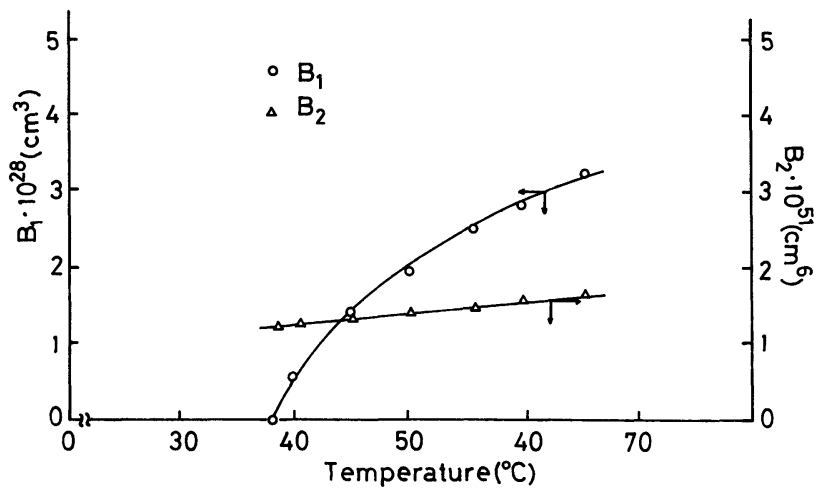

Fig. 2. - Temperature dependences of $B_{1}$ and $B_{2}$.
From the figure we were able to determine the values of $B_{1}$ and $B_{2}$ for various temperatures near the $\theta$ temperature. Here, we have used the value of $A=0.7 \AA$ as given in the literature [4]. The temperature dependency of $B_{1}$ and $B_{2}$ is shown in figure 2 . It is remarkable that the behaviours of the cluster integrals $B_{1}$ and $B_{2}$ bear a strong resemblance to those of second and third virial coefficients of an imperfect gas near its Boyle temperature. We see that the prediction of the scaling theory by Daoud and Jannink [5]

$$
\xi^{-2} \sim C^{2}
$$

is valid in the immediate neighbourhood of the $\theta$ temperature. In the close vicinity of the $\theta$ temperature, $B_{1}$ is expected to behave as

$$
B_{1}=B_{0}\left(1-\frac{\theta}{T}\right)
$$

As shown in figure $3, B_{1}$ as a function of $1-\theta / T$ is not linear over a wide temperature range. The initial slope of figure 3 gives the value $B_{0}=8 \times 10^{-27} \mathrm{~cm}^{3}$. Finally, we note that the value of $Z_{2}$ is about 0.01 and is almost independent of temperature, whereas the value of $Z_{1}$ is less than unity up to about $60^{\circ} \mathrm{C}$. The smallness of $Z_{2}$ indicates that the contribution of $B_{2}$ to the chain dimensions of polystyrene in cyclohexane is very small and the conformation of polystyrene chains in dilute solutions of cyclohexane is essentially unperturbed at the $\theta$ temperature.

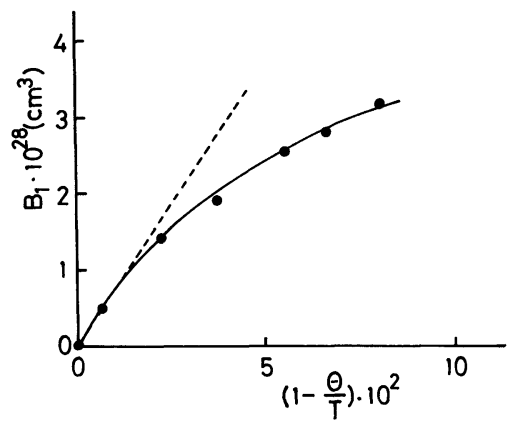

Fig. 3. - Variation of $B_{1}$ with $\left(1-\frac{\theta}{T}\right)$. The full straight line shows the initial tangent and has a slope of $8 \times 10^{-27} \mathrm{~cm}^{3}$.

\section{References}

[1] Okano, K., Wada, E., Kurita, K. and Fukuro, H., J. Appl. Crystallogr. 11 (1978) 134.

[2] Moore, M. A., J. Physique 38 (1977) 265

[3] Cotton, J. P., Nierlich, M., Boué, F., Daoud, M., Farnoux, B., Jannink, G., Duplessix, R. and Picot, C., J. Chem. Phys. 65 (1976) 1101.
[4] Yamakawa, H., Modern Theory of Polymer Solutions (Harper and Row, NY) 1971.

[5] Daoud, M. and Jannink, G., J. Physique 37 (1976) 973. 